After examining the parts in their natural position, I removed them, and hastened home to place the whole in warm water. Then, having cleared the plicenta of as much blood as possible, taking care that the water in the basin remained warm and clean, I injected into the umbilical vein a large quantity of warm water coloured. This was done with the intention of learning whether any of it would pass into the water in the basin through the large gaping sinuses on the cut surfaces of the uterine walls. I have frequently failed to inject placentre from the difficulty of getting them whole; but with this one, no portion of the utero-placental connexions being disturbed, I was enabled to distend it to a considerable size, and, after a long time, some of the injection oozed back through the umbilical arteries. Although I continued injecting coloured fluid for upwards of an hour, the water in the basin remained colourless, except indeed being slightly tinged with a littleblood that, notwithstanding the pressure I had employed, still remained in the uterine vessels. No portion of the coloured injection passed beyond the placental vessels. This proves, or I should rather say, in deference to the experiments of others, stupports the position, that no fluids by means of bloodvessels can pass from the child to the mother. I now made an opening on the external surface of the uterus, corresponding to about the centre of the placenta, and having found a large artery, I threw into it an injection, consisting. for the sake of its running freely, of a small proportion of yellow wax melted in olive oil. After injecting as much of the oil and wax as it was possible to get in, that part of the examination was left for the next day.

It now occurred to me that I should like to see the uteroplacental arteries and veins, or anything else lying or passing between the placenta and uterus. On very carefully lifting the edge of the placenta, and raising its substance for a few inches from the internal face of the uterus, using at the time a powerful magnifying glass, I found that, instead of having torn through arteries and veins, leaving large open mouths, which have been supposed to be the frightful source of uterine hæmorrhage, there was really nothing of the kind to be seen. The placenta appeared to be merely in apposition with the uterine decidua, and kept there by the means already alluded to, aided probably to some extent by a very slight and imperfect stratum of cellular tissue. The uterine surface of the placenta, covered by a thin, imperfect membrane, by some called the placental decidua, was not entireiy free from marks of blood, but these were only small points, almost as few and as far between as the red points seen on making a section of the brain. I am quite aware that in the practice of midwifery we sometimes find the placenta saturated with blood, but this appearance arises from a cause which I am able to explain; and is it not an argument in favour of my views, that after ordinary labours we frequently find the uterine surface of the placenta almost as free from blood as in this case, where it had not to pass through the natural passages? To proeed with the examination. It must be remembered that the uterine decidua as yet remained perfect. Finding a little bulging at a certain part of it, about an inch from the border of the placental attachment, I made a small incision, and immediately a portion of the injection which $I$ had thrown in at the back of the uterus made its appearance. On the following day, the injection having hardened, I dissected the uterine substance from without to within. I found the injection in several parts, but the greater portion was deposited in lumps, about the size of filberts, on the uterine decidua. The sacculi containing the injection seemed to be formed by processes of the decidua fixed to the uterine walls, forming septa between them; they were irregular in size and form. It was one of these sacculi that $I$ had noticed the day before, on the other side of the decidua, by its bulging appearance.

In the substance of the uterus, I found that the bloodvessels lose their distinctive characters of arteries and veins from without inwards. The inner third is made up entirely of a network of sinuses, without any larger arteries and veins than those necessary for the nutrition of the parts in which they are found. These are the small vessels, or continuations of them, and therefore still smaller, that pass through the uterine decidua, the rupture of which gave rise to the points of blood seen on the uterine surface of the placenta; they are similar to the vessels of new tissues, mere minute canals, as imperfectly organized as the tissues they are intended to nourish. All this goes to prove that fluids do not pass from the mother to the child directly by-means of bloodvessels; and also that there are no utero-placental arteries and veins, the rupture of which can give rise to what we call uterine hæmorrhage. Where, then, does the blood come from? My conviction is, that when the placenta is removed, the sacculi $I$ have spoken of become over-distended with blood, and burst; the membrane forming them is easily torn, and one after the other they give way. But by this time the onter muscular fibres of the uterus have probably contracted, which, by preventing more blood from being sent into the sinuses, and these themselves being interlaced with contractile fibres, their calibre is obliterated, and the hrmorrhage is arrested. The gush of blood which sometimes comes down upon the hand of the accoucheur, $I$ believe arises from the sudden bursting of one of these sacculi. It is difficult to imagine that the open mouths of either arteries or veins could produce such a result. These, however, the proper bloodvessels of the uterus, are comparatively remote from the surface exposed by the removal of the placenta; they only communicate with it indirectly through the uterine sinuses, which form a supplementary and different kind of circulation. The communication of the uterine arteries and veins with the sinuses is somewhat similar to that of the pudic arteries and veins with the corpus cavernosum. The uterine sinuses may be said to some extent to represent the same structure on a larger scale; and I believe that the uterine arteries and veins have no more to do with uterine hemorrhage from the removal of the placenta than the pudic arteries and veins would have with hæmorrhage from an exposed surface proportionate in size - of the corpus cavernosum.

1 think I have shown that the mere removal of the placenta cannot possibly give rise to hæmorrhage. It can only be regarded as an indirect cause of that occurrence, which, after all, is nothing more than a matural and healthy process, a disgorgement of the over-strained sinuses, and, except in a lax and unfavourable condition of the uterus, interfering but little with the general circulatory system of the mother. Formerly, I often wondered at the immense losses of blood which women sometimes sustained with impunity. Now, knowing that large portions during pregnancy are made unnecessary to the mother, and as far as regards quantity, gradually as it were removed from her system, my wonder is much dininished.

Fearing I shall occupy too much space, I must leave for another occasion much that I have to say on the minute anatomy of the uterus, the microscopical appearances of the utero-placental connexions, the physiology of the placenta, and the bearings of the whole on the practice of midwifery.

Howland-street, Fitzroy-square, 1856.

REPORT OF A CASE OF

\section{OBSCURE PAIN IN THE EPIGASTRIUM OF A LITTLE CHILD.}

By ROBERT C. CROFT, Esq., M.R.C.S.

A srort time ago I was requested to see a little girl, five years of age, who had been suffering (so the mother stated) from pain, apparently very severe, in the epigastrium. On my arrival, however, the child appeared perfectly well, and, with the exception of a furred tongue snd somewhat dry skin, I could detect no symptoms whatever.

Upon questioning the mother, I elicited that a day or two before the little girl had eaten a small portion of pickle, and to this, therefore, we attributed the pain, and $I$ ordered her a purgative and some febrifuge mixture.

Next day, the report was that the patient had passed a very restless night, and had at intervals complained of the same pain, which, according to the mother's description of the child during the paroxysms, must have been severe. When I saw her, however, beyond the furred tongue and dry skin, nothing was to be noticed - no tenderness upon pressure, or, indeed, any symptom one conld seize upon. This state of things continned for five days, and when asked to state what was the matter with the child, I declined, on the plea that I really did not know.

On the fifth day, I ordered a more powerful purgative of jalap, scammony, and calomel, thinking the irritation might be owing to worms in the intestinal canal. On the following morning she passed a corroded percussion cap! All pain and uneasiness at once ceased, and the child was well.

Remarlss. - Would the percussion cap have produced so much pain supposing no pickle had been eaten? or did the vinegar, acting on the copper, produce all the mischief? or is the composition used in the cap poisonous?

This case is curious, and deserves record, 1st, because it shows how easily children may pick up and eat poisonou 
things, without being in the remotest degree suspected of having done anything of the kind; and 2ndly, because it shows how careful medical men ought to be that their diagnoses are eorrect before they venture to state the name of the complaints from which patients, and especially children, are suffering.

Melville-terrace, Camden-town, Feb. 1856.

\section{a detlitrot}

OF THE PRACTICE OF

\section{MEDICINE AND SURGERY IN THE}

\author{
HOSPITALS OF LONDON.
}

Nulla est alia pro certo noseendi via, nisi quam plurimas ct morborum at dissectionum historias, tam aliorum proprias, collectas habere et int
se comparare.-Mongagr. De Sed. et Caus. Morb. lib. 14. Procmium.

\section{ST. GEORGE'S HOSPITAL.}

\section{PRIMARY AMPUTATIONS.}

Iv a recent "Mirror" we adverted to the comparative dangers of primary and secondary amputations, and briefly mentioned the somewhat contradictory declarations of certain recent statistical tables on the subject. It is to be lamented that at present no definite rules for practice in many cases have been ascertained, to which the practitioner can look for instruction, when, between caution and enterprize, he is unable to decide on the proper course to be pursued. In surgery, where it is especially necessary to disregard the celebrated dogma of Fuler, "this is contrary to all experience, and yet it is true," the method by which to dispel uncertainty and error is to make a wise use of the results of the past, taking care our view be as comprehensive as possible, and that we do not found arguments on insufficient data. It is, therefore, with satisfaction, that we avail ourselves of the opportunity afforded us by a communication from Mr. Holmes, the surgical registrar of St. George's Hospital, of making public the experience of that institution with regard to primary amputations during the past year.

CASE 1.-A man aged twenty-eight, of healthy aspect and temperate habits, injured his right ancle by a severe fall on the foot. On admission, the end of the tibia was projecting through the skin, and was entirely denuded for the length of two inches and a half. The soft parts in the neighbourhood were so much lacerated that amputation was peremptorily demanded; the flap operation therefore was performed as near the wounded part as possible. It was found that the fibula had been fractured as well as the tibia, the extreme encis of both bones remaining attached to the ligaments. The man went on well till the twelfth day, when rigors, succeeded by perspirations, occurred. These, however, ceascd after the bowels had been relieved by aperient medicine, and no other unfavourable symptoms displayed themselves till the twentietl day, when pain in the chest and left kree, together with changed complexion, indicated the existence of pyohamia. From this time he sank rapidly; a large abscess was opened in the knee-joint before his death, which occurred on the twenty-seventh day. Post-montem Exumination. - There was secondary deposit in the lungs and pus in the right external iliac vein, liver, knee, and cellular tissue around the bladder.

CAse 2.-.-A man, aged forty-one, of intemperate habits, was admitted with compound fracture through the internal condyle of the right humerus into the elbow-joint, and laceration of the brachial artery, together with extensive injury to the soft parts, The acciclent was caused by the casual explosion of a fowling-piece, close to the man's arm. Ail the shot seemed to have passed through the limb; primary amputation by the circular method was performed; the artery was found torn completely across, but had not bled to any considerable amount though the man had been brought up from the conntry, a distance of some ten miles. He had one or two attacks of secondary hremorrhage, not however very severe, during the first week. His pulse was feeble and irritable, tongue white, skin hot, and manner singular. Te had a bad cough, attributed to cold caught on the day of the accident. On the ninth day 206 the stump was attacked with sloughing, which, however, was quickly checked, but left him excessively weak and with low delirium. Nevertheless, he improved during the following week, after which frequent rigors and sweats marked the advent of secondary inflammation, and soon an abscess vresented itself in the right foot. He died on the twenty-ninth day after the operation.

Post-mortem Examination.-Abscess in the tarsal joints and secondary deposit in the lungs.

CASE 3.-A man, aged thirty-four, was admitted on the 5th of November, with a gun-shot wound received in the thigh from the explosion of a small cannon with a ramrod in it, the latter passing through the thigh. He was apparently in perfect health, and of sound constitution. The account of the accident, and subsequent amputation of the limb, and dissection of the parts, was given on November 6 th to the Patholological Society by Mr. Prescott Hewett. Nuch foul discharge came from the stump, and considerable irritative fever followed the operation, but the case progressed favourably. When he left the hospital on the sixty-second day, the stump was not quite healed, there being a ring of necrosed bone at the end of the femur, which was as yet quite firmly fixed.

CASE 4. There was one more case of primary amputation during the last year in the hospital. It was that of a healthy lad, aged sixteen, whose foot had been lacerated in a threshing. machine. The leg was amputated by the circular incision. The boy died of pyohæmia (secondary pneumonia and jus in pleural cavity) on the twenty-ninth day. No visceral disease was found.

THE REMOVAL OF SEQUESTRA FROM THE POPLITEAL SPACE.

$$
\text { (Under the care of Mr. Cutuer.) }
$$

On the 18th of October Mr. Cutler removed a very large sequestrum from the lower third of the femur-a situation, we believe, peculiarly liable to disease and death of the bone. The case was one of no ordinary importance, as from the extent of the diseased tissues it was a question in consultation whether the limb should not be removed high up at the thigh. Six months previous to Mr. Cutler's operating an effort was made to remove the portion of bone, but the sequestrum had not then become loose. On this occasion, however, the whole of it was removed.

The following are our notes of the case, in which were in. volved, in our opinion, some nice points of practical and conservative surgery:-

The patient, a young woman, aged twenty-nine, and of a healthy aspect, had been troubled for the last thirteen years with extensive necrosis of the thigh-bone, accompanied by profuse discharge. The disease was confined to the lower and back part of the limb, where there were several sinuses leading down to the bone. The knee presented the appearance of partial dislocation. The joint was fixed in the semi-flexed position, and the inner condyle of the femur projected considerably. There had been no accident, and the only history the patient could give of hex affection was, that some thirteen years back an abscess had made its appearance, without any apparent cause, at the back of the thigh. In the course of four months this abscess burst, and several pieces of bone had since then at different times come away.

Such was the state of affairs when the woman first came to the hospital in March last, and shortly after her admission it was decided that an attempt should be made to remove the dead bone; but, after freely layino open the parts, the bone proved to be so firmly fixed that its removal was abandonee for a time. The wound commenced sloughing, and soon a large piece of bone became exposed.

So the case went on for sone six months, when the surgeons of the hospital detemined, in consultation, that another attempt should be made to get the bone out; and that if this failed, the limb shonld be removed, as the patient was evidently losing ground. The operation, as we before stated, was performed on the 18th of October, 1855

The sequestrum, a large piece of which could be seen, was known to pass down immediately in front of the popliteal ressels; and, in the course of the operation, it was ascertained that the popliteal artery, in the greater part of its length, was only separated from the bone by some condensed tissues. With extreme exertion, Mr. Cutler succeeded in splitting ap the large sequestrum into several pieces, all of which were got out after no little trouble. One or two of these pieces extended as far down as the knee-joint itself, and required excessive care in the removal.

That the popliteal artery was in danger during the operation, especially in drawing out the fragments, there can be no doubt. 